\title{
NATIONAL FITNESS TRENDS
}

\section{Anastasiia VOROBIOVA ${ }^{1 *}$, Marina VASYLENKOํㅜ, Nadiia VYSOCHINA ${ }^{2}$}

\author{
${ }^{1}$ National University of Physical Education and Sport, Kyiv, Ukraine \\ 2 "Ivan Chernyakhovskyi" National Defence University of Ukraine, Kyiv, Ukraine \\ *Corresponding author: Anastasiia-99@bigmir.net
}

DOI: 10.35189/iphm.icpesk.2019.52

\begin{abstract}
The fitness industry is one of the most profitable in the world and attractive to investing. The competitiveness of a fitness club depends on the speed of implementing the latest trends. The purpose of our study is to compare the world and national trends. The most popular kinds of fitness in the world in 2019, according to experts from the American College of Sports Medicine, will be: wearable technology; group training; high-intensity interval training (HIIT); fitness programs for older adults; bodyweight training; employing certified fitness professionals; yoga; personal training; functional fitness training; exercise is medicine; health/wellness coaching. The comparison of world (the USA, China, Spain) and national trends in 2018 has made it possible to find that global trends reflect the USA trends in a proportion of 95\% and only half of the trends in other represented countries. This is due to the fact that, in a study of the American College of Sports Medicine with representatives from 41 countries, 91.3\% of respondents were from the United States. This confirms the need to study national trends rather than focus on "world" trends, as they mainly reflect the prospects of development in one country (the USA). This statement is true for the fitness trends in 2019, according to a research conducted in Spain, where again only 60\% of trends are equal to the results of the world ranking.
\end{abstract}

Keywords: fitness, trend, development, perspective, world and national trends.

\section{Introduction}

The sphere of fitness develops dynamically, which is why the cycle of existence of one direction in fitness (from the idea of its expansion to the peak of popularity and its decline) may take less than 10 years. This is connected first with the development of additional fitness equipment, based on the use of which the new directions of fitness appear. Thus, in Ukraine, people have started relatively recently to use the Procedos platform, SUPplatform, ViPR and TRX Rip Trainers, suits for EMS (Electro Muscular Stimulation) fitness, which leads to the appearance and development of new fitness directions, though some of them have been actively developing abroad for a long time. Instead, some fitness directions lose their actuality (for example, shaping).

Tendencies change quickly, which is conditioned by the commercial orientation of the fitness industry (Müller et al., 2012). In order to be competitive, fitness clubs and fitness trainers must be permanently updated and implement novelties. In the sphere of fitness, it is simply impossible to study one fitness direction at a time and use it in the training sessions throughout life, because clients become more and more educated and demanding, show strong dislike for monotony and are easily ready to change a trainer, a club or a direction of training.

Every year, starting from 2006, specialists from the American College of Sports Medicine (ACSM) conduct an electronic poll of lead specialists in the sphere of fitness from around the world in order to find out what types of fitness would be popular the next year.

The first such research was published by Thompson (2006), in which the author described the trends for 2007. That year, the Top 10 included the following directions: children and obesity; special fitness programs for older adults; educated and experienced fitness professionals; functional fitness; core training; strength training; personal training; mind/body exercise; exercise and weight loss; outcome measurements.

Similar research was conducted in certain countries: Spain (Veiga, Valcarce Torrente, \& King Clavero, 2017; Veiga, Valcarce Torrente, King Clavero, \& de la Cámara, 2018), China (Yongming, Yang, Han, Miao, \& Li, 2018), Hungary (Müller et al., 2012). Nowadays, there is a question of a geographic growth of specifically national studies of fitness trends, as every country has its own specificity, historical and cultural particularities and preferences (Kercher, 2018).

World tendencies in the fitness sphere cannot be applied to each country. For example, the gap in the fitness industry in Ukraine is 5 years behind the world for big cities, but in small towns and the countryside, sometimes the fitness culture is completely missing.

That is why there is a need to research the state of the fitness industry in each country and the perspectives of its development. 


\section{Material and Methods}

The research is based on both the analysis of sources in the literature and the thoughts of experts concerning the perspectives of fitness development. Scientific articles and statistical information were analysed to compare the world trends in fitness development with the national ones. Data from Spain, China and the USA were taken for comparison. Extracts presented in the analysed papers are described in the discussion of the research.

\section{Results}

In 2019, for the thirteenth time, a survey of lead specialists concerning fitness directions that will be the most popular has been conducted. Two thousand and thirty-eight experts from Australia, Canada, China, France, Germany, Great Britain, India, Italy, Japan, Russia, Singapore, Taiwan and the USA responded to it. The qualification of respondents is proven by the following facts: $27 \%$ of them have an experience of 10-19 years, and $33 \%$ - over 20 years; the annual income of $45 \%$ of the respondents totals over 50000 USD, including $9 \%$ with the income over 100000 USD; $69 \%$ of the respondents work full time, $25 \%$ - less than 20 hours per week. Besides, representatives of various organizations (private practice or own business - $35 \%$, hospital or medical centre program or department $-20 \%$, commercial fitness centres $-17 \%$, university recreation centres $-13 \%$, etc.) and professions (personal trainer $-18 \%$, clinical exercise physiologist $-10 \%$, health/fitness director $-10 \%$, professor $-9 \%$, health fitness specialist $-7 \%$, medical professional $-6 \%$, etc.) responded to the poll. (Thompson, 2018)

Thirty-nine possible trends were suggested, among which the newest ones were: virtual reality, community interventionist and Access Pass, but none of them reached the Top 20. The names of some directions were specified or changed: large group training to group training; dance workouts - dance-based workouts; wellness coaching - health/wellness coaching; mobile phone exercise apps - mobile exercise apps (because clients also use applications on other devices); worksite health promotion - worksite health promotion and workplace well-being programs. Strength training was removed from the questionnaire, because this was a very broad term. Employing certified fitness professionals replaced a more abstract position: educated, certified and experienced fitness professionals.

The 20 global fitness trends of 2019 (Thompson, 2018) are:

1) wearable technology (trackers, SMART watches, GPS devices);

2) group training (more than 5 people in a group);

3) high-intensity interval training (HIIT - intervals of high-intensity work followed by a short period of rest);

4) fitness programs for older adults (determined by the world trends of living longer, working longer and remaining active and healthy much longer);

5) bodyweight training (a combination of concentric and eccentric movements with neuromotor movements in various planes without additional weights);

6) employing certified fitness professionals (certification programs allow employers to evaluate easily the quality of professional competencies: expertise, knowledge and skills);

7) yoga (a variety of forms);

8) personal training (includes fitness testing, goal setting with the trainer and immediate workouts in a club, online, at home or at the workplace);

9) functional fitness training (includes strength training and other types of activities to improve balance, coordination, strength and endurance for the daily routine; some respondents have underlined that they combine this concept with fitness programs for older adults or rehabilitation programs);

10) exercise is medicine (EIM - a global initiative concerning the healthcare, which is focused on encouraging medical workers to assess physical activity and provide appropriate recommendations in this regard, as well as to refer their patients to professional trainers);

11) health/wellness coaching (focused on healthy lifestyle habits, using intervention strategies for behavioural changes and considering the client's values, needs, mindset, short- and long-term goals; it is conducted individually or in small groups and includes the support of a coach, goal setting, recommendations and motivation);

12) exercise for weight loss (a combination of physical exercise with nutrition programs; in 2019, special emphasis is placed on the combination of diets, diet pills and cooking lessons with physical exercise); 
13) mobile exercise apps (visual and sound accompaniment to perform exercise, track progress and many other functions);

14) mobility/myofascial devices (includes rollers for self-massage, pain relief in trigger points, alleviation of muscular discomfort, strain and cramps, myofascial release, increase in blood flow, assistance for returning to normal activity);

15) worksite health promotion and workplace well-being programs (this program is provided at the initiative of employers to improve the health and well-being of employees and is integrated with systems of evaluation and reporting on the state of health, expenses and productivity);

16) outcome measurements (this tendency is based on attempts to define, trace and notify about the training outcomes in order to assess the efficiency of a program, document success in changing habits related to a negative lifestyle; the development of technologies promotes the enhancement of this trend);

17) outdoor activities (comprise outdoor training sessions: group walks, travels or organized tourist groups; they can be 24-hour short events or planned week excursions);

18) licensure for fitness professionals (regulation of quality fitness services with the help of licensure in certain countries);

19) small group personal training (a switch from the "one-on-one" training to small group training (2 to 5 people) allows to lower the cost of the training for a client, but increases it for the trainer);

20) postrehabilitation classes (training programs purposely designed for patients with chronic diseases, such as cancer, cardiovascular disease, Parkinson's disease and stroke recovery, who have already completed a rehabilitation program in medical centres; they can also include posttraumatic disorders that can be observed in soldiers - combat veterans). (pp. 12-15)

In comparison with the year 2018, the three leaders are still the same, but high-intensity interval training has moved from the first to the third position, and wearable technology, from the third to the first position. Three directions that were presented among the trends in 2017, but were no longer popular in 2018 - mobile exercise apps $\left(13^{\text {th }}\right.$ place $)$, worksite health promotion and workplace well-being programs $\left(15^{\text {th }}\right.$ place $)$ and outcome measurements $\left(16^{\text {th }}\right.$ place $)$ reached the Top 20. A new direction in 2019 will be postrehabilitation classes $\left(20^{\text {th }}\right.$ place $)$, which were in the ratings only in 2011 ( $18^{\text {th }}$ place $)$, being called "Clinical integration/ Medical fitness", which is close to the definition of EIM (Exercise is Medicine).

Nevertheless, as it has already been said, the world trends will not correspond to the national ones. Thus, for example, outdoor programs are quite popular in Ukraine, but they are only seasonal, and the training programs for older adults, which have occupied the $4^{\text {th }}$ place in the world ranking, are practically insufficient on the fitness service market in Ukraine. A prominent emphasis on the certification and licensure of fitness professionals is made all around the world, while in Ukraine, the process of establishment of the Unified fitness standard has just begun, and the only criterion is to hold a higher education degree in the field of fitness and recreation or certificates proving the completion of different courses. That is why there is a sense in conducting similar research in certain countries.

Kercher (2018) tried to compare the research conducted in China (Li et al., 2018) and Spain (Veiga et al., 2018) with the results obtained in the USA in 2018 (Table 1).

Table 1. Comparative analysis of fitness trends in the world, the USA, China and Spain in 2018 (A revised and enlarged analysis after Kercher, 2018)

\begin{tabular}{|c|c|c|c|c|}
\hline \multirow{2}{*}{ No. } & \multicolumn{4}{|c|}{ Trends in 2018} \\
\hline & World & United States & China & Spain \\
\hline 1. & $\begin{array}{l}\text { High-intensity interval } \\
\text { training }\end{array}$ & Group training & Strength training & $\begin{array}{l}\text { Educated, certified and } \\
\text { experienced fitness } \\
\text { professionals }\end{array}$ \\
\hline 2. & Group training & $\begin{array}{l}\text { High-intensity interval } \\
\text { training }\end{array}$ & Wearable technology & Functional fitness \\
\hline 3. & Wearable technology & Wearable technology & Youth sports* & Exercise and weight loss \\
\hline 4. & Body weight training & Strength training & Body weight training & $\begin{array}{l}\text { High-intensity interval } \\
\text { training }\end{array}$ \\
\hline 5. & Strength training & Bodyweight training & Outdoor activities & Personal training \\
\hline 6. & Educated, certified and & Educated, certified and & Core training & Bodyweight training \\
\hline
\end{tabular}




\begin{tabular}{|c|c|c|c|c|}
\hline & $\begin{array}{l}\text { experienced fitness } \\
\text { professionals }\end{array}$ & $\begin{array}{l}\text { experienced fitness } \\
\text { professionals }\end{array}$ & & \\
\hline 7. & Yoga & Yoga & Group training* & Outcome measurements * \\
\hline 8. & Personal training & Personal training & $\begin{array}{l}\text { Physical and medical } \\
\text { education* }\end{array}$ & $\begin{array}{l}\text { Smartphone exercise } \\
\text { apps* }\end{array}$ \\
\hline 9. & $\begin{array}{l}\text { Fitness programs for } \\
\text { older adults }\end{array}$ & $\begin{array}{l}\text { Fitness programs for } \\
\text { older adults }\end{array}$ & $\begin{array}{l}\text { Educated, certified and } \\
\text { experienced fitness } \\
\text { professionals }\end{array}$ & $\begin{array}{l}\text { Fitness programs for older } \\
\text { adults }\end{array}$ \\
\hline 10. & Functional fitness & Functional fitness & Walking and jogging* & Group personal training \\
\hline 11. & $\begin{array}{l}\text { Exercise and weight } \\
\text { loss }\end{array}$ & $\begin{array}{l}\text { Exercise and weight } \\
\text { loss }\end{array}$ & $\begin{array}{l}\text { Worksite health } \\
\text { promotion* }\end{array}$ & Core training \\
\hline 12. & Exercise is Medicine & Exercise is Medicine & $\begin{array}{l}\text { Licensure for fitness } \\
\text { professionals }\end{array}$ & $\begin{array}{l}\text { Multidisciplinary working } \\
\text { teams* }\end{array}$ \\
\hline 13. & $\begin{array}{l}\text { Group personal } \\
\text { training }\end{array}$ & $\begin{array}{l}\text { Group personal } \\
\text { training }\end{array}$ & $\begin{array}{l}\text { Smartphone exercise } \\
\text { apps* }\end{array}$ & $\begin{array}{l}\text { Seeking new market } \\
\text { niches* }\end{array}$ \\
\hline 14. & Outdoor activities & Outdoor activities & $\begin{array}{l}\text { Children and exercise for } \\
\text { the treatment or } \\
\text { prevention of obesity* }\end{array}$ & Strength training \\
\hline 15. & $\begin{array}{l}\text { Flexibility and } \\
\text { mobility rollers }\end{array}$ & $\begin{array}{l}\text { Flexibility and } \\
\text { mobility rollers }\end{array}$ & Yoga & Group training* \\
\hline 16. & $\begin{array}{l}\text { Licensure for fitness } \\
\text { professionals }\end{array}$ & $\begin{array}{l}\text { Licensure for fitness } \\
\text { professionals }\end{array}$ & $\begin{array}{l}\text { Sports nutrition } \\
\text { guidance* }\end{array}$ & Wearable technology \\
\hline 17. & Circuit training & Circuit training & Personal training & $\begin{array}{l}\text { Specific exercise programs } \\
\text { for the ill* }\end{array}$ \\
\hline 18. & Wellness coaching & Wellness coaching & Fitness social clubs* & Outdoor activities \\
\hline 19. & Core training & Core training & Exercise and weight loss & Circuit training \\
\hline 20. & Sport-specific training & Indoor cycling* & Outcome measurements* & $\begin{array}{l}\text { Exercises for prevention of } \\
\text { and recovery from } \\
\text { injuries* }\end{array}$ \\
\hline
\end{tabular}

Note: *trends that have not featured the world rating.

Analysing the data in Table 1, we can notice that the results of the world study in 2018 are practically identical with the USA results. This can be explained by the fact that the world research on the 2018 fitness trends (Thompson, 2017) included 4133 respondents from 41 countries: Argentina, Australia, Barbados, Bermuda, Brazil, Canada, Chile, China, Columbia, Ecuador, Egypt, Finland, Germany, Greece, India, Ireland, Israel, Italy, Jamaica, Japan, Kenya, Lebanon, Malaysia, Mexico, New Zealand, Philippines, Portugal, Romania, Serbia, Singapore, South Africa, South Korea, Spain, Sweden, Switzerland, Taiwan, Thailand, United Arab Emirates, United Kingdom, the United States, and Venezuela.

At the same time, according to the data of Kercher (2018), 3775 (91.3\%) respondents were from the USA. This information was not mentioned by Thompson in his articles (Thompson, 2017, 2018). That is why the world trends reflect in their majority the USA trends. As a difference, we can mention the $20^{\text {th }}$ position of the trends in the USA in 2018, cycling, which has not featured in the world rating. The other positions are identical. This underlines the necessity of studying national trends once again.

Let us analyse the situation in China and Spain, as presented in the national research. Only 10 fitness trends in China and 13 trends in Spain coincide with the world tendencies. Among the national trends that are not present in the world rating, 3 are common for China and Spain: outcome measurements, group training, Smartphone exercise apps. As for the "unique" tendencies, in China, there are youth sports, physical and medical education, walking and jogging, worksite health promotion, children and exercise for the treatment or prevention of obesity, sports nutrition guidance, fitness social clubs; in Spain, multidisciplinary working teams (doctors, physical therapists, nutritionists and experienced certified professionals in the sphere of physical training and sports) are seeking new market niches, specific exercise programs for the ill, exercises for prevention of and recovery from injuries. In such a way, it is possible to observe that, in Spain, a significant attention is paid to a rehabilitation direction of fitness, while, in China, this tendency is practically missing. Also in China, the sport direction is more popular. 
This means that the national trends better represent tendencies of a certain country and will not coincide with the world trends (though it happened to be that the world trends are practically the USA trends).

The results of a study regarding the 2019 fitness trends in Spain have already been published (Veiga, Valcarce Torrente, King Clavero, \& de la Cámara, 2019). This year, the most popular directions are: educated, experienced and qualified professionals; functional fitness; exercise and weight loss; personal training; high-intensity interval training; bodyweight training; training under the guidance of professional fitness trainers; training programs for older adults; core training; outcome measurements; multidisciplinary working teams; strength training; smallgroup personal training; seeking new market niches; children and exercise for the treatment or prevention of obesity; exercises for prevention of and recovery from injuries; mobile exercise apps; circuit training. And again, 8 out of the 20 positions of the national rating do not coincide with the world ones.

The most comprehensive study attempting to evaluate the state of fitness industry in Ukraine, in 2017, was conducted, for the first time, by FitnessConnectUa - an informational and analytical platform for the monitoring, study and forecasting in the sphere of fitness. The results of their research were taken into account in the annual international report of the "European Health \& Fitness Market" (2018). In the pan-European rating, Ukraine occupied the $11^{\text {th }}$ position by the quantity of fitness clubs and the $12^{\text {th }}$ position by the quantity of consumers.

The fitness market in Ukraine is only shaping, because the consumers of fitness services are less than 3\% of the Ukrainian population. That is why Ukraine has a great potential for the fitness industry development. Specialists of FitnessConnectUa think that providing the economic conditions and tax environment would be a favourable aspect, and the quantity of fitness consumers might double.

However, a major study on the forecasting of future fitness trends in Ukraine has not been conducted yet, but at the conference "The Current State of Fitness Industry in Ukraine and Perspectives of Its Development" and at the presentation "Research of the Market of Fitness Services in Ukraine", which were held on the $26^{\text {th }}$ of June 2018 in Kyiv, experts and trainers specified some positions that should be developed in Ukraine and that would be able to become trends in the future.

Thus, the Vice President of the Ukrainian Fitness Association, Vadym Gumenyuk, emphasises 4 main categories: consumer market trends, in which he underlines that children are our future and that is why it is necessary to actively develop youth sports and fitness; labour market trends, in which there is a redistribution and an incremental growth of experts' responsibility and a change in role of a fitness trainer; infrastructure trends, in which the necessity of the state and private partnership and the development of municipal initiatives, with the legislative support of the state, are stressed; fitness trends, in which the most popular type is exercise and weight loss.

Vladyslav Syla, the Head of the "Ukrainian New Health Technologies Centers" Association puts an emphasis on the fact that consumers of fitness services are becoming more conscious and that is why, first of all, it is necessary to pay attention to the quality and safety of fitness services. Also, he points out the prospective development of fitness directions for older adults, but stresses that Ukrainian clubs, unfortunately, are not ready to provide quality services for them. Dmytro Chornyi, the founder and the Head of a chain of fitness clubs, "Malibu", who has implemented free memberships for senior citizens, does not agree to this statement. He underlines that the mentality of the older generation becomes the main obstacle to the development of this direction, especially on a paid basis.

The Head of the "FitCurves" International Office, Iryna Kravtsova, has marked the necessity of co-operating with the Ministry of Health of Ukraine, especially when it is concerned with working out the nutrition guidance, as far as, in her opinion, traditions of nutrition in each individual family have a major influence on the nation's health. A partner of the company group "Sport Life", Maksym Zaretskyi, has stressed that the fitness mission is to guarantee the nation's health and that is why it is necessary to expand the fitness culture to the maximum in every city of Ukraine. He also mentioned the problem of trainer certification, which was discussed by other specialists too.

The outcomes of the conference have not been ineffective, because, at the beginning of 2019, the initiative of the Unified fitness standard of Ukraine development was presented. This is a shared project of the National University of Physical Education and Sport in Ukraine and the analytical and consulting FitnessConnectUa platform.

By analysing the thoughts of Ukrainian experts, it can be seen that they draw more attention to problems whose solution will give a positive boost to the development of fitness in Ukraine. As for possible trends, there are only certain hypotheses. 


\section{Conclusion}

The dynamic development of the fitness sphere requires fitness clubs and fitness trainers to be constantly updated and to implement novelties in their activity to stay competitive.

Specialists of the American College of Sports Medicine conduct annually, starting from 2006, a survey among experts from different countries in order to define trend directions in fitness for the next year. The results are annually published in the ACSM's Health \& Fitness Journal, and specialists all over the world are guided by them. However, a more detailed study of the respondents' excerpts showed that, in 2017, while establishing trends for 2018, 4133 people from 41 countries responded to the poll, but $91.3 \%$ were representatives of the USA. That is why the results of the study reflect, in a proportion of $95 \%$, a picture of popular directions in the USA (only one direction, which occupies the $20^{\text {th }}$ position, does not correspond to the world trends), but not worldwide.

This is proved by considering identical national research studies conducted in China and Spain, which coincide with the world ones only by half and have their own peculiarities typical for each country. We can say for sure that the world trends will not reflect the situation in any country, which is why there is a need to conduct similar studies in each country by attracting lead experts.

In Ukraine, the sphere of fitness and its possible perspectives of development are being actively studied, and the making of the Unified fitness standard has started, which will allow improving the quality of services and will facilitate the shaping of fitness culture and healthy lifestyle among the population in big cities and the countryside.

\section{References}

European Health \& Fitness Market: Report 2018. (2018). Cologne, Germany. Retrieved from https://www2.deloitte.com/content/dam/Deloitte/de/Documents/consumerbusiness/European\%20Health\%20and\%20Fitness\%20Report_2018_extract.pdf

Kercher, V. M. (2018). International comparisons: ACSM's worldwide survey of fitness trends. ACSM's Health and Fitness Journal, 22(6), 24-29. doi: 10.1249/FIT.0000000000000431

Müller, A., Biro, M., Hidvegi, P., Vaczi, P., Plachi, J., Juhasz, I., ... János, S. (2012). Fitness trends in recreation. Acta Academiae Agriensis, XL, 25-34. (In Hungarian). Retrieved from http://publikacio.unieszterhazy.hu/754/1/25-34_Muller.pdf

Thompson, W. R. (2006). Worldwide survey reveals fitness trends for 2007. ACSM's Health and Fitness Journal, 10(6), 8-14. http://dx.doi.org/10.1249/01.FIT.0000252519.52241.39

Thompson, W. R. (2017). Worldwide survey of fitness trends for 2018: The CREP Edition. ACSM's Health and Fitness Journal, 21(6), 10-19. DOI: 10.1249/FIT.0000000000000341

Thompson, W. R. (2018). Worldwide survey of fitness trends for 2019. ACSM's Health and Fitness Journal, 22(6), 10-17. DOI: 10.1249/FIT.0000000000000438

Veiga, O. L., Valcarce Torrente, M., \& King Clavero, A. (2017). National survey of fitness trends in Spain for 2017. Apunts Educacio Fisica y Deportes, 128(2), 108-125. (In Spanish). Retrieved from https://www.researchgate.net/publication/318226159_National_Survey_of_Fitness_Trends_in_Spain_for_201 7

Veiga, O. L., Valcarce Torrente, M., King Clavero, A., \& de la Cámara, M. A. (2018). National survey of fitness trends in Spain for 2018. Retos, 33, 279-285. (In Spanish). Retrieved from https://www.researchgate.net/publication/322626261_Encuesta_Nacional_

de_Tendencias_de_Fitness_en_Espana_para_2018

Veiga, O. L., Valcarce Torrente, M., King Clavero, A., \& de la Cámara, M. A. (2019). 2019 National survey of fitness trends in Spain. Retos, 35, 341-347. (In Spanish). Retrieved from https://www.researchgate.net/publication/329681682_Encuesta_Nacional_de_Tendencias_de_Fitness_en_Espa na_para_2019

Yongming, L., Yang, L., Han, J., Miao, L. V., \& Li, X. (2018). 2018 China fitness trend survey report. Retrieved from https://howtobehealthyforme.wordpress.com/2018/09/28/which-fitness-methods-are-most-populartoday? -chinas-fitness-trend-released-in-2018/ 